\title{
Methylenelactide: vinyl polymerization and spatial reactivity effects
}

\author{
Judita Britner and Helmut Ritter ${ }^{*}$
}

\section{Full Research Paper}

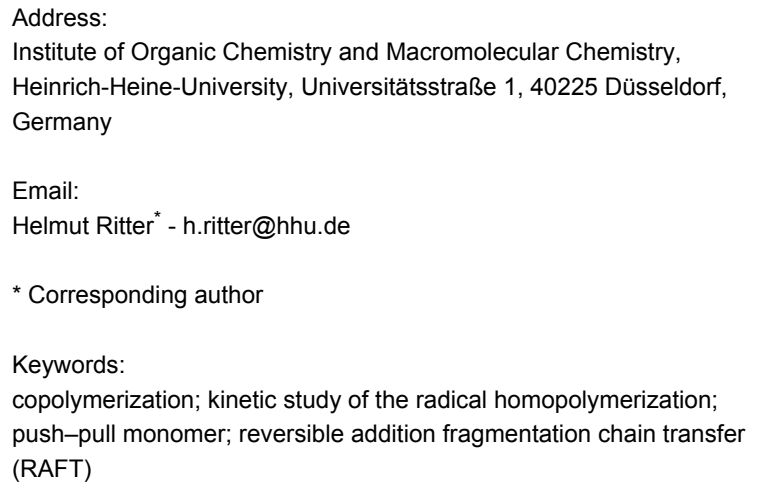

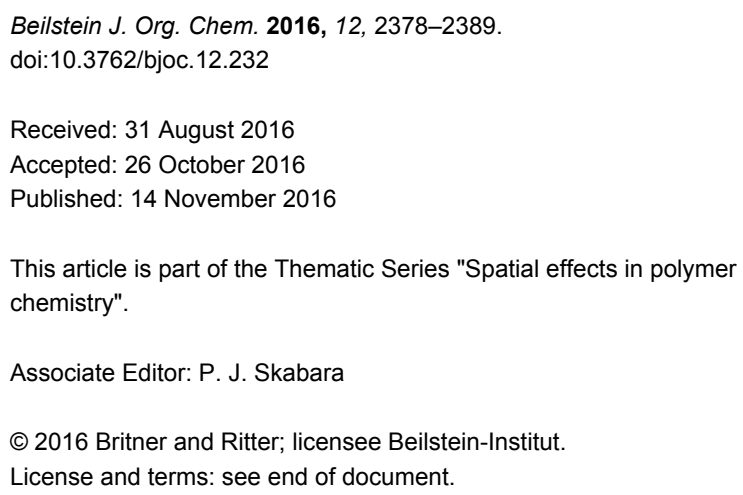

\begin{abstract}
The first detailed study on free-radical polymerization, copolymerization and controlled radical polymerization of the cyclic push-pull-type monomer methylenelactide in comparison to the non-cyclic monomer $\alpha$-acetoxyacrylate is described. The experimental results revealed that methylenelactide undergoes a self-initiated polymerization. The copolymerization parameters of methylenelactide and styrene as well as methyl methacrylate were determined. To predict the copolymerization behavior with other classes of monomers, $Q$ and $e$ values were calculated. Further, reversible addition fragmentation chain transfer (RAFT)-controlled homopolymerization of methylenelactide and copolymerization with $N, N$-dimethylacrylamide was performed at $70{ }^{\circ} \mathrm{C}$ in 1,4-dioxane using AIBN as initiator and 2-(((ethylthio)carbonothioyl)thio)-2-methylpropanoic acid as a transfer agent.
\end{abstract}

\section{Introduction}

Methylenelactide (MLA) with the IUPAC name (6S)-3-methylene-6-methyl-1,4-dioxane-2,5-dione is a radically polymerizable vinyl-lactide derivative. The molecule's quaternary carbon atom located at the double bond is substituted with an electron withdrawing ("pulling") carbonyl group and an electron donating ("pushing") oxygen atom. Monomers with such substitution patterns are defined as captodative or push-pull monomers [1]. MLA was first synthesized in 1969 by Scheibelhoffer et al. through a bromination of L-lactide followed by a basic $\mathrm{HBr}$ elimination [2]. In 2008, the first Diels-Alder reaction employing MLA as dienophile was described [3-6]. In a recent NMR study we demonstrated that, poly(MLA) prepared via free radical polymerization contains mainly isotactic units. Furthermore, we found that the polymer attached lactide rings react like activated esters and thus readily undergo quantitative amidation reactions with aliphatic primary amines under mild conditions [7]. In the underlying study, we focused on spatial effects with respect to interactions between neighboring lactide rings. Based on these findings, polymer analogous reactions of poly(MLA) with different alcohols were recently investigated [8]. Up to now, it was not possible to polymerize MLA via ring opening [9]. Only indirectly, unsaturated polylactide carrying 
vinyl side groups can be obtained through a copolymerization of chlorolactide with L-lactide followed by subsequent dehydrochlorination [10]. Recently, thiol-Michael additions on MLA were reported $[11,12]$.

In this paper, we wish to present a kinetic study of free radical and controlled/living radical polymerization of MLA. The latter reactions were conducted via a reversible addition fragmentation chain transfer (RAFT) mechanism. We also investigated the copolymerization of MLA with styrene and methyl methacrylate, respectively. The results were compared to the wellknown push-pull type monomer $\alpha$-acetoxyacrylate.

\section{Results and Discussion Free-radical polymerization of methylenelac- tide MLA}

The push-pull type monomer MLA contains an electron-deficient vinyl group which is structurally related to acrylate monomers. Electron-rich vinyl groups are structurally related to vinyl ester monomers. However, the free-radical polymerization of MLA proceeds smoothly at elevated temperature without ringopening side reactions (see Figure S1 in Supporting Information File 1). To evaluate the free-radical polymerization of MLA, we compared the behavior to non-cyclic, pull-type methyl methacrylate (MMA), non-cyclic, push-pull-type methyl $\alpha$-acetoxyacrylate (MAA) and ethyl $\alpha$-acetoxyacrylate (EAA), respectively and cyclic pull-type $\alpha$-methylene- $\delta$-valerolactone (MVL, see Figure 1).

Since the polymerization kinetics are mainly controlled by steric effects and the polarity of the double bonds, we evaluated the electronic structure of the different monomers via ${ }^{1} \mathrm{H}$ nuclear magnetic resonance (NMR) spectroscopy. As expected, the double bond protons of MLA at 5.77 and $5.56 \mathrm{ppm}$ clearly differ from the double bond protons of MAA (6.02 and $5.65 \mathrm{ppm}$ ) and EAA (5.99 and $5.62 \mathrm{ppm}$ ). Surprisingly, their chemical shifts are very similar to the double bond protons of MMA (6.03 and $5.66 \mathrm{ppm}$ ). This suggests that the electronwithdrawing substituent has a stronger influence on the electron density of the vinyl protons than the electron-pushing substituent (Table S1, Figures S2 and S3, Supporting Information File 1). We further employed ${ }^{13} \mathrm{C}$ NMR spectroscopy to provide a better view on the electron density of the double bond. It turned out that the quaternary carbon atoms of the double bond of EAA (144.31 ppm), MAA (144.04 ppm) and MLA (143.69 ppm) experience a stronger impact through the electron-withdrawing substituent than the corresponding carbon atoms of MMA (135.77 ppm) and MVL (134.09 ppm). The electron-pushing substituent influences preferentially the methylene carbon atom. This methylene carbon atom shows a relatively high electron density in case of MLA (108.31 ppm), MAA (114.67 ppm,) and EAA (114.32 ppm) compared to the lower electron density in MMA (125.59 ppm) and MVL (127.74 ppm) (Table S1 and Figure S3, Supporting Information File 1).

The homopolymerization reactions were carried out in presence of $1 \mathrm{~mol} \%$ of AIBN at $70{ }^{\circ} \mathrm{C}$. The conversion after different reaction times was determined via ${ }^{1} \mathrm{H}$ NMR spectroscopy (Figure 1). The molecular weights and dispersities $(\nexists)$ of the obtained polymers are summarized in Table S2 (Supporting Information File 1).

Interestingly, the polymerization kinetics of MLA are similar to these of MMA. In contrast, the non-cyclic push-pull type monomers MAA and EAA are both less reactive. This indicates that in addition to steric hindrance, the mobility of the substituents plays an important role in the spatially controlled<smiles>C=C(C)C(=O)OC(C)=O</smiles>

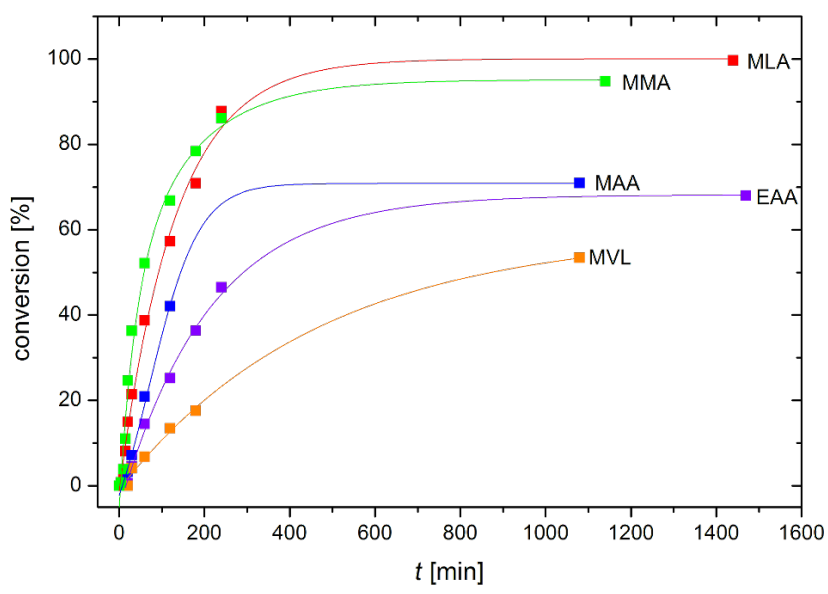

Figure 1: Structures of used monomers and the time-conversion plot of the corresponding free-radical polymerization reactions (80 wt \% DMF, $1 \mathrm{~mol} \%$ AIBN, $\left.70^{\circ} \mathrm{C}\right)$. 
chain growth reactions. The molecular weights $\left(M_{\mathrm{n}}\right)$ are $21600 \mathrm{~g} \mathrm{~mol}^{-1}$ for poly(MAA) and $31600 \mathrm{~g} \mathrm{~mol}^{-1}$ for poly(EAA) with narrow dispersities $(\nexists)$ between 1.5 and 1.7, indicating that chain termination mainly occurs through recombination of polymer radicals [13].

The moderate conversion of MVL is presumably a result of the relatively low ceiling-temperature of the corresponding polymer (at $81{ }^{\circ} \mathrm{C}$ ) [14]. This means that under the applied reaction conditions the rate of the polymerization reaction is only slightly higher than the depolymerization rate, which results in slow polymer growth. The obtained data also indicates that the electron densities of the vinyl groups of the used monomers play a minor role with respect to the polymerization kinetics. The higher mobility of the free substituents of the non-cyclic push-pull type monomers MAA and EAA causes a reduced polymerization rate (Figure 1) compared to that of the stiff cyclic molecule MLA.

\section{Stereochemistry of poly(MLA)}

As we reported recently, MLA polymerizes via free-radical polymerization to yield predominantly isotactic polymer structures (Figure S4, Supporting Information File 1). Similar findings were reported by Tanaka et al. who investigated the poly- merization of methylene dioxolanone derivatives yielding predominantly isotactic polymers [15]. Our recently reported spatial dipole-dipole interactions between neighboring lactide units were supported by IR spectroscopy, as the interactions causes two separate carbonyl stretching vibrations. This effect may also play a crucial role in the isotactic propagation steps during MLA polymerization [7]. In contrast, the polymer of non-cyclic MAA shows a preferred syndiotactic ( $r r)$ conformation caused by steric control of the free substituents as indicated by ${ }^{13} \mathrm{C}$ NMR spectroscopy (Figure S5, Supporting Information File 1). Scheme 1 shows the different potential propagation steps of MLA.

\section{Deviation of classical polymerization kinetics of MLA}

Usually, the rate of polymerization is proportional to the square root of initiator concentration [In] and the degree of polymerization $\left(P_{\mathrm{n}}\right)$ is inversely proportional to the square root of [In]. To investigate the polymerization behavior of MLA at $70{ }^{\circ} \mathrm{C}$, different molar amounts of AIBN were used. The polymerization reactions were evaluated after ca. 2 minutes at low conversions up to $10 \%$ as determined by ${ }^{1} \mathrm{H}$ NMR spectroscopy. The precipitated polymers were analyzed by size exclusion chromatography (SEC) in DMF (Table 1). The logarithmic plot

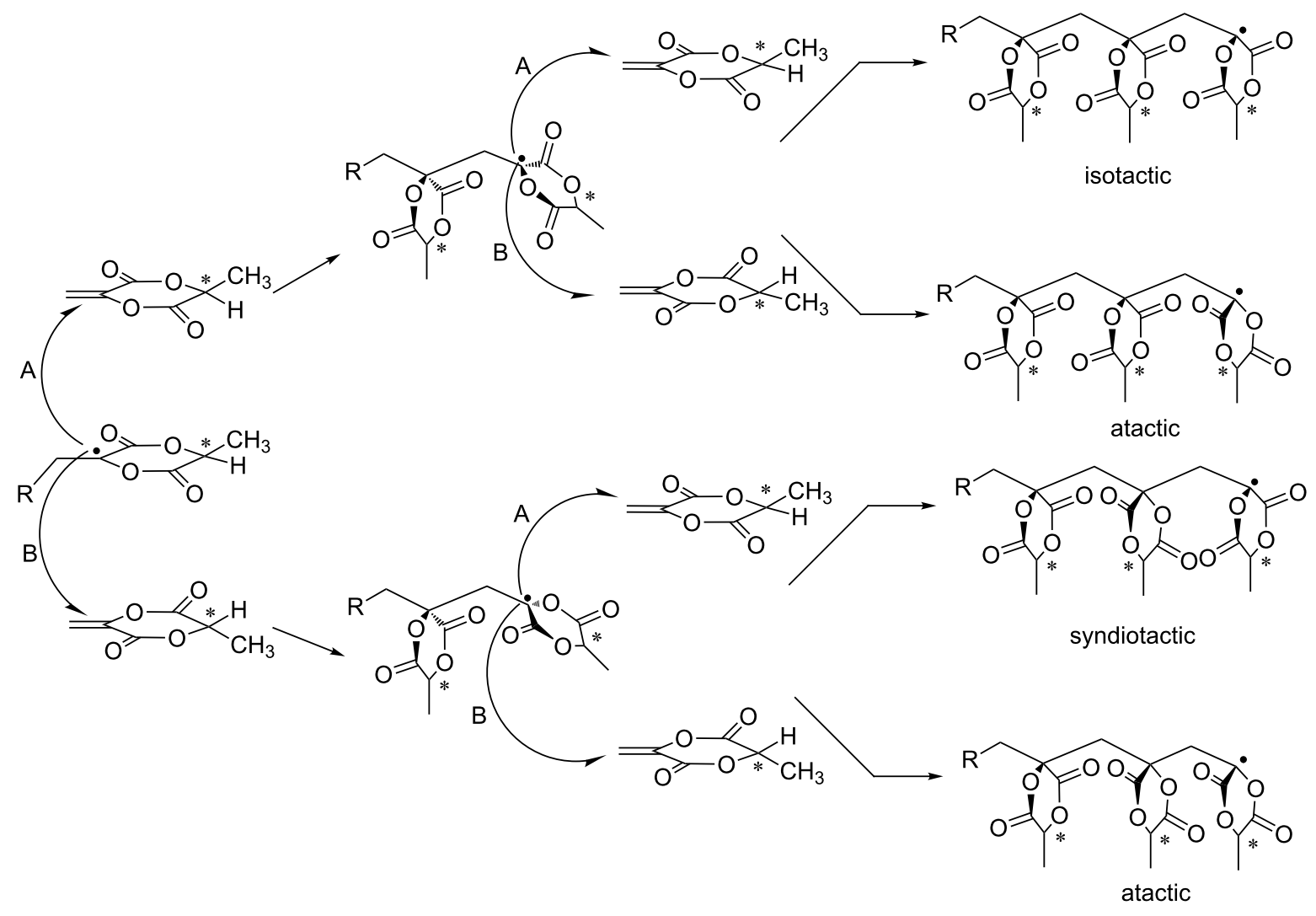

Scheme 1: Stereospecific propagation of chiral MLA illustrating the triade formation [15]. 
Table 1: SEC data from the polymerization of MLA with different amounts of AIBN $\left(c_{(\mathrm{MLA})}=1.812 \mathrm{~mol} \mathrm{~L}^{-1}\right.$ in $1,4-$ dioxane, $15-1 \mathrm{~mol} \%$ AIBN, $70{ }^{\circ} \mathrm{C}$, polymerization time 2 minutes).

\begin{tabular}{ccccccc} 
sample & 1 & 2 & 3 & 4 & 5 & 5 \\
\hline$\frac{[\mathrm{AIBN}]}{\mathrm{mol} \mathrm{\%}}$ & 15 & 12.5 & 10 & 7.5 & 5 & 2.5 \\
$\frac{M_{\mathrm{n}}}{\mathrm{g} / \mathrm{mol}}$ & 35600 & 46800 & 47600 & 62200 & 85400 & 158800 \\
$Ð$ & 1.8 & 5.7 & 4.6 & 3.4 & 5 & 2.7
\end{tabular}

displayed in Figure 2 shows the correlation between the degree of polymerization and the initiator concentration. The slope was determined to be -0.84 , which significantly deviated from the expected value of 0.5 . This observation indicates some self-initiation beside AIBN initiation.

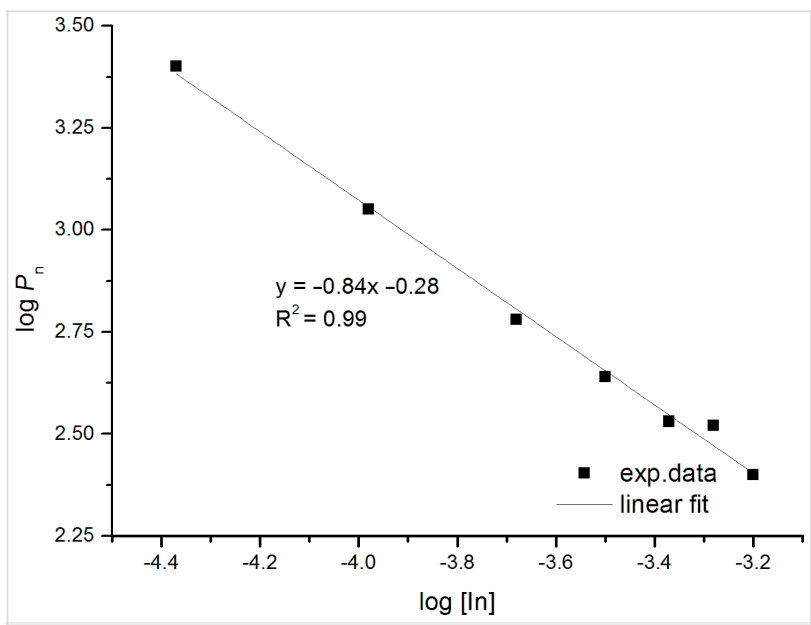

Figure 2: Plot of $\log P_{\mathrm{n}}$ versus $\log [\mathrm{In}]$ of the polymerization of MLA with different $\mathrm{mol} \%$ AIBN.

\section{Self-initiation of MLA}

The self-initiation of some non-cyclic push-pull monomers is already known [1]. However, up to now, the free radical selfinitiation of cyclic MLA has not been described in the literature. Thus, we herewith show our postulated mechanism for the selfinitiation of MLA in Scheme 2. We propose that a homolytically $\mathrm{H}-\mathrm{C}$ cleavage takes place in a first step yielding two radicals. This process is accompanied by a change of hybridization from a tetrahedral $\mathrm{sp}^{3}$ structure of the chiral center to a trigonal planar $\mathrm{sp}^{2}$ structure of the resulting radical. Scheme 2 also shows additional postulated radical reactions including the formation of a bicyclic lactide radical to initiate the main polymerization. Since the spontaneous homolytically $\mathrm{C}-\mathrm{H}$ cleavage may represent the first step in the reaction cascade, theoretical calculations on a DFT level were conducted. The above mentioned hybridization change as driving force for $\mathrm{C}-\mathrm{H}$ cleavage is verified in the reduced bond length of the $\mathrm{C}-\mathrm{CH}_{3}$ bond from
$1.542 \AA$ (MLA) to $1.479 \AA$ for the corresponding radical. This clearly indicates a stabilization of this $\mathrm{C}-\mathrm{C}$ bond after $\mathrm{C}-\mathrm{H}$ cleavage (Figure 3).

Since only soluble polymers were obtained, the $\mathrm{C}-\mathrm{H}$ bonds in the linear MLA-polymer units must be more stable than in the monomeric MLA. Otherwise, crosslinking should take place via spontaneous $\mathrm{C}-\mathrm{H}$ cleavage and chain recombination. This important point could be verified by IR spectroscopy and also by theoretical calculations of the force constants of the $\mathrm{C}-\mathrm{H}$ bonds on a DFT level.

The $\mathrm{C}-\mathrm{H}$ stretching vibrations $v_{(\mathrm{C}-\mathrm{H})}=2948 \mathrm{~cm}^{-1}$ of poly(MLA) determined via IR spectroscopy correlate well with the force constant of $k=473 \mathrm{~N} \mathrm{~m}^{-1}$ (calculations see Figure S6, Supporting Information File 1). In contrast, the monomer MLA $\left(v_{(\mathrm{C}-\mathrm{H})}=2938 \mathrm{~cm}^{-1}\right)$ has a significantly lower force constant of $k=467 \mathrm{~N} \mathrm{~m}^{-1}$. This also gives a strong hint on the postulated relatively easy $\mathrm{C}-\mathrm{H}$ homolytical cleavage from MLA as described in Scheme 2. This measured IR values correspond nicely to the DFT calculations (poly(MLA) $v_{(\mathrm{C}-\mathrm{H})}=2922 \mathrm{~cm}^{-1}$, MLA $\left.v_{(\mathrm{C}-\mathrm{H})}=2914 \mathrm{~cm}^{-1}\right)$. Figure 4 shows the IR spectra of MLA and of the obtained poly(MLA).

To evaluate some kinetic solvent effects of the discussed selfinitiated polymerization reactions of MLA, the kinetics of the AIBN-initiated and initiator-free radical polymerizations of MLA were repeated in less polar 1,4-dioxane and dipolar DMF as solvents (Figure 5). Surprisingly, the yields of self-initiated polymerization in 1,4-dioxane are very similar to the yields of AIBN-initiated polymerization. In contrast, the self-initiation polymerization of MLA is much more retarded in DMF solution than in 1,4-dioxane. Taking our postulated radical formation process into account, the dipolar solvent DMF stabilizes the polar educt MLA more than the less polar 1,4-dioxane. Since the formed radical is planar and less polar, the activation energy to this radical formation must be higher in DMF than in 1,4-dioxane [16]. Interestingly, the self-initiated poly(MLA) has a relatively high molecular weight of $M_{\mathrm{n}}=180000 \mathrm{~g} \mathrm{~mol}^{-1}$ $(\nexists=2.5)$ compared to the AIBN initiated poly(MLA) 


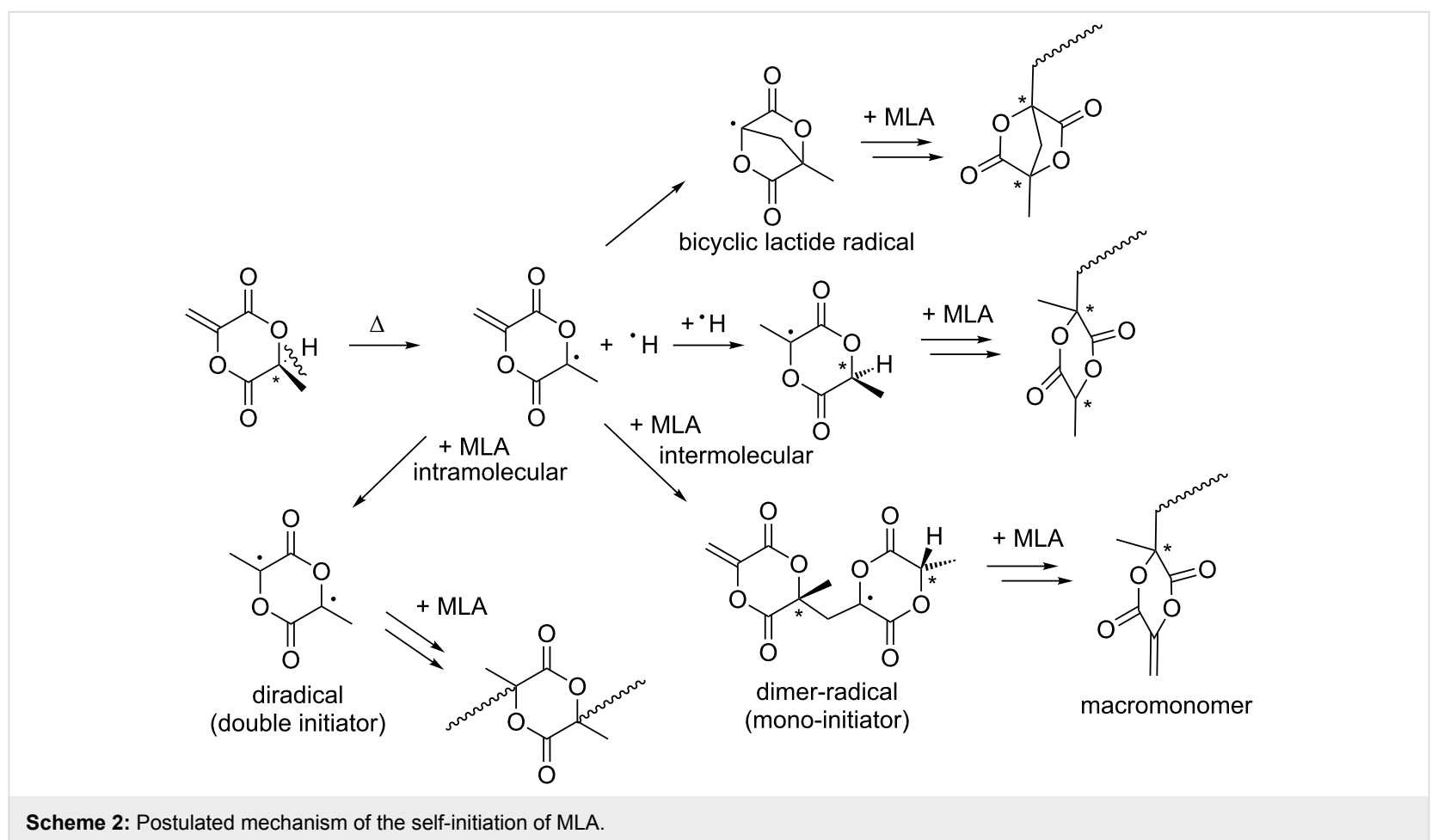

Scheme 2: Postulated mechanism of the self-initiation of MLA.

A)

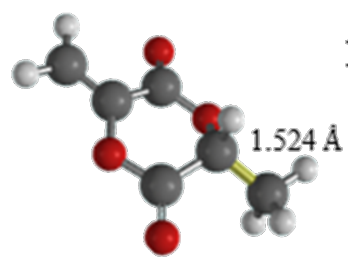

B)

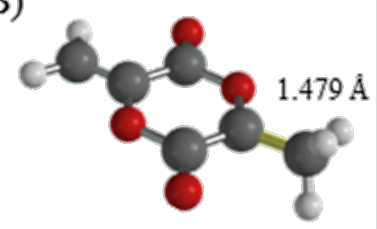

Figure 3: DFT-calculated C-C binding length (yellow) of (A) MLA and (B) the corresponding radical.

$\left(M_{\mathrm{n}}=73000 \mathrm{~g} \mathrm{~mol}^{-1}, \oslash=2.6\right)$. A self-initiated poly(MLA) obtained at $30{ }^{\circ} \mathrm{C}$ yields with a reduced molar mass of $M_{\mathrm{n}}=28600 \mathrm{~g} \mathrm{~mol}^{-1}, D=1.9$ (Figure S7, Supporting Information File 1). Poly(MLA) polymerized in DMF could not be analyzed by SEC because of some unknown side products (Figure S8, Supporting Information File 1).

For comparison, the non-cyclic MAA shows even in bulk only a very low yield of ca. $10 \mathrm{~mol} \%$ of self-initiated polymer at $60{ }^{\circ} \mathrm{C}[13,17]$. Thus, the ring shaped MLA is much more reactive in respect to the self-initiated polymerization.

\section{Calculated initial rate for the self-initiated polymerization of MLA by the use of DPPH}

As discussed above, the formation of free radicals is a key step for spontaneous polymerization of MLA. Accordingly, spontaneously formed radicals can be proved by the use of the strongly colored 1,1-diphenyl-2-picrylhydrazyl radical (DPPH) which reacts with $\mathrm{H}$ radicals under decolorization. The consumption of DPPH-radicals can be followed by the naked eye. Figure 6 shows the UV-vis absorption spectra of DPPH from the beginning of the self-initiated polymerization at $70{ }^{\circ} \mathrm{C}$ and after $15 \mathrm{~h}$.

The concentration of DPPH plotted against the time at $70{ }^{\circ} \mathrm{C}$ and $30{ }^{\circ} \mathrm{C}$ gives a straight line indicating that the reaction follows pseudo zero-order kinetics (Figures S10 and S11, Supporting Information File 1). The slope of this plot corresponds to the reaction rate. The reaction rate of disappearance of DPPH $\left(R_{\mathrm{DPPH}}\right)$ is equal to the value of the rate of MLA self-initiation $\left(R_{\mathrm{i}}\right)$. Accordingly, at $70{ }^{\circ} \mathrm{C}$ the self-initiated polymerization with a rate of $2.4 \times 10^{-4} \mathrm{mM} \mathrm{s}^{-1}$ is 5 times higher than at $30^{\circ} \mathrm{C}$ with a rate of $4.42 \times 10^{-5} \mathrm{mM} \mathrm{s}^{-1}$ (Figure S12, Supporting Information File 1). The actual polymerization reaction takes place after DPPH was consumed, since the molecule acts as an inhibitor. In a control experiment performed in absence of MLA, the DPPH concentrations remained stable.

\section{Free radical copolymerization behavior of MLA}

The copolymerization parameters of MLA with styrene and MMA, respectively were evaluated through the method of Kelen and Tüdös [18]. For this, the residual monomer ratio was determined by high performance liquid chromatography (see execution, characterization methods and Figures S14 and S15 in Supporting Information File 1). 

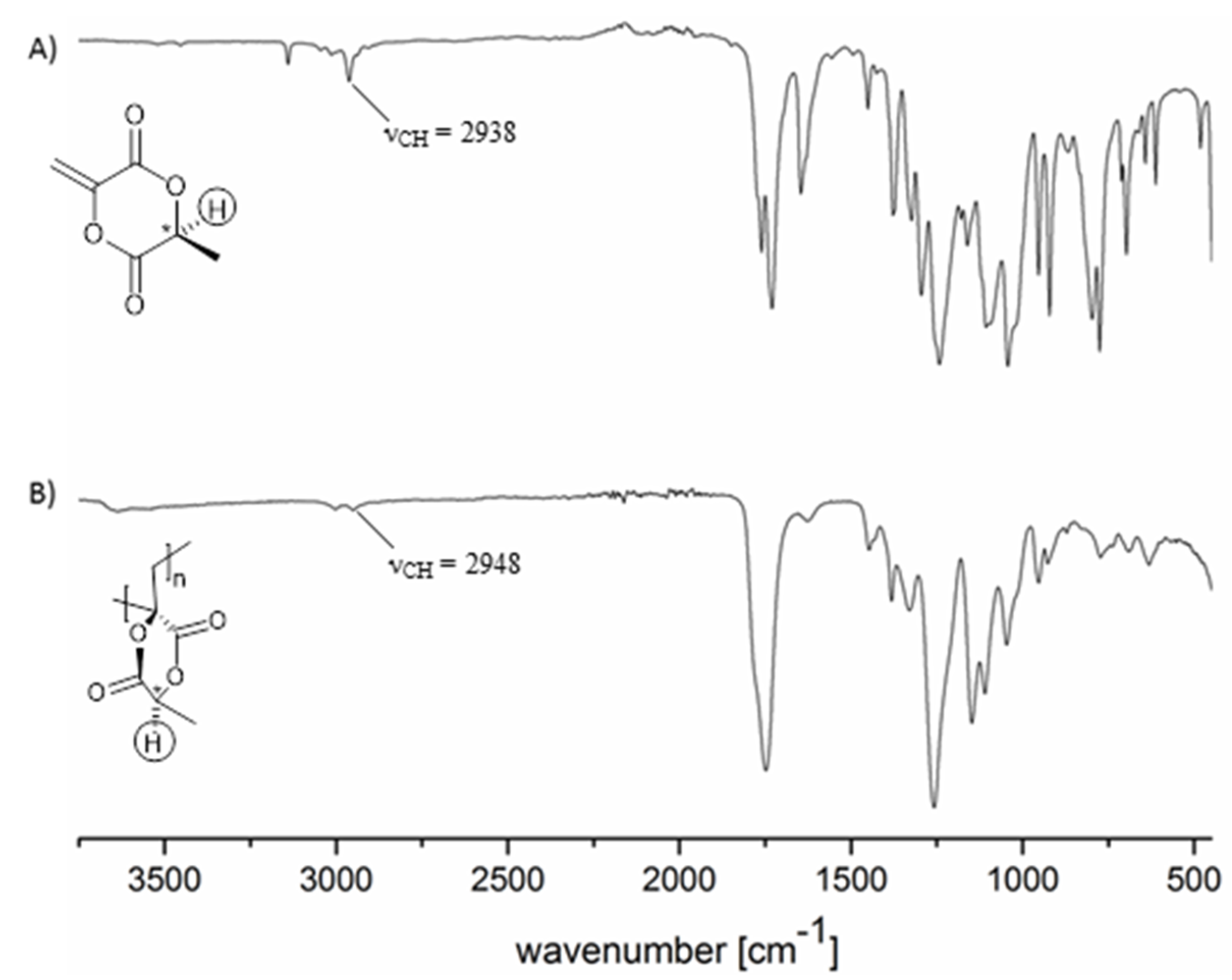

Figure 4: IR spectra of $(A) M L A$ and of $(B)$ poly(MLA) prepared by the self-initiated polymerization at $70^{\circ} \mathrm{C}$.

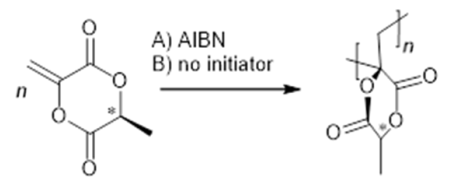

A)

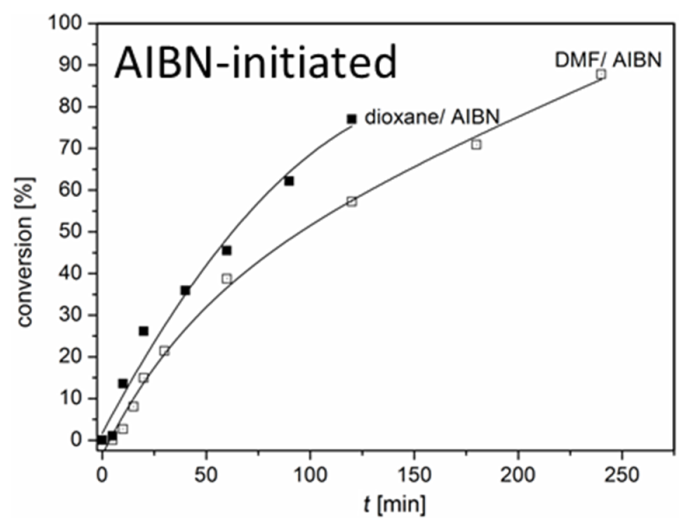

B)

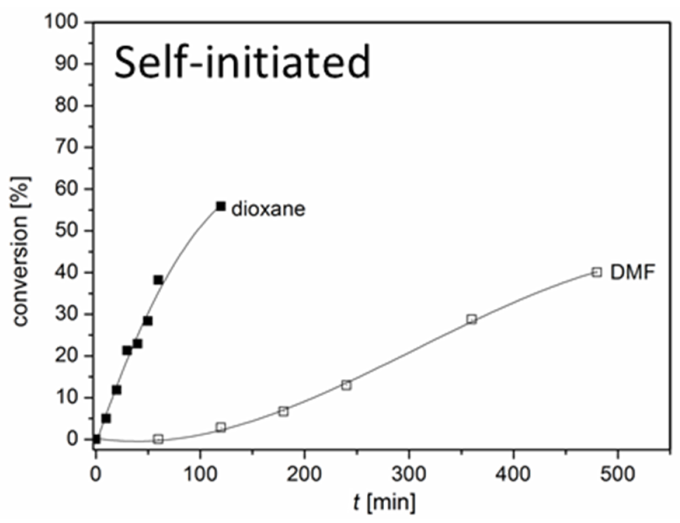

Figure 5: Conversion plot of the polymerization of MLA in 1,4-dioxane and DMF $\left(c_{\mathrm{MLA}}=1.8 \mathrm{~mol} \mathrm{~L}^{-1}, c_{\mathrm{AIBN}}=1.8 \times 10^{-2} \mathrm{~mol} \mathrm{~L}-1,70{ }^{\circ} \mathrm{C}\right)$ with $\mathrm{AIBN}(\mathrm{A})$ and without initiator $(B)$.

The copolymerization parameters obtained from the MLA and styrene system were $r_{1}=0.8$ (MLA) and $r_{2}=0.7$ (styrene) which indicates that the copolymerization process proceeds partially alternating. The Alfrey-Price $Q$ and $e$ values were also calculated from the experimental data. The values for MLA are $Q=0.79$ and $e=0.015$ (see Figure $\mathrm{S} 16$ for $Q$ and $e$ value calcu- 


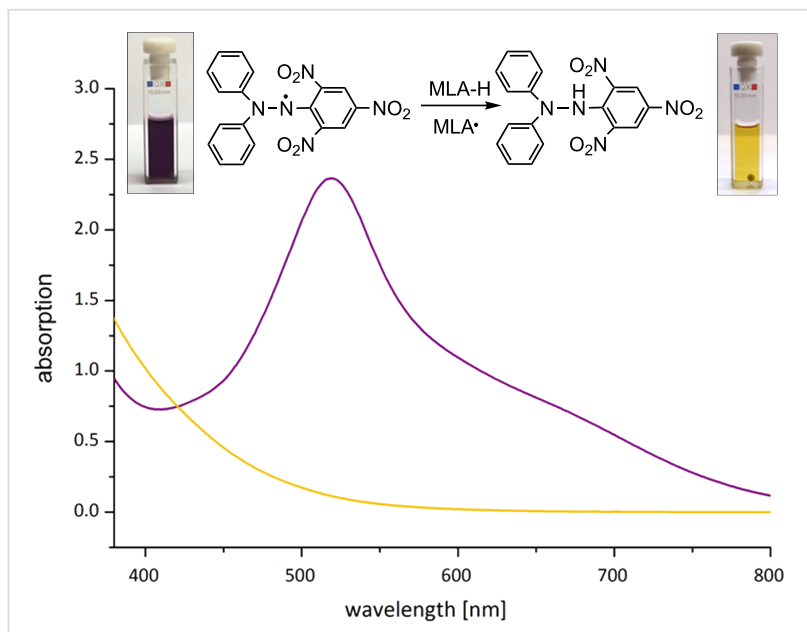

Figure 6: UV-vis spectra of the reaction mixture with DPPH radical at the beginning (violet line, $0.23 \mathrm{mM}$ ) of the self-initiated polymerization of MLA and after $15 \mathrm{~h}$ (yellow line) in a range from $380-800 \mathrm{~nm}$ $\left(c_{\mathrm{MLA}}=1.8 \mathrm{~mol} \mathrm{~L}^{-1}, 70^{\circ} \mathrm{C}\right)$.

lation, Supporting Information File 1) [19]. The constant $Q$ reflects the resonance stabilization of the growing radical. Large $Q$ values ( $>0.5)$ indicate stabilized monomers. The constant $e$ reflects the polarity of the double bond and of the growing radical. For instance positive $e$ values point to an electrophilic character while negative $e$ values point to a nucleophilic character.

In contrast, the non-cyclic monomers MAA and EAA show higher positive $e$ values and are thus highly influenced by the pull substituents. These higher $e$ values are also indicated in the ${ }^{13} \mathrm{C}$ NMR data described above and by higher dipole moments in MAA (3.79 Debye) and EAA (2.26 Debye) compared to MMA (4.10 Debye) and MLA (2.09 Debye) (refer to Table S1, Supporting Information File 1). The $Q$ and $e$ values of various monomers are summarized in Table 2 [20-22].

Table 2: Alfrey-Price $Q$ and $e$ values of various monomers with styrene as reference system.

\begin{tabular}{lll} 
Monomer & $Q$ & $e$ \\
\hline styrene & 1 & -0.8 \\
MLA & 0.79 & 0.015 \\
MMA & 0.78 & 0.40 \\
MAA & 1.65 & 0.57 \\
EAA & 0.52 & 0.77 \\
vinyl acetate & 0.026 & -0.88 \\
$N, N$-dimethylacrylamide (DMAa) & 0.55 & -0.56
\end{tabular}

The copolymerization parameters obtained from MLA and MMA were $r_{1}=1.1$ (MLA) and $r_{2}=1.2$ (MMA) which indicate an almost statistical process, with a slight tendency to homoadditon. Figure 7 illustrates the obtained copolymer composition curves for the systems of MLA with styrene and MMA, respectively.

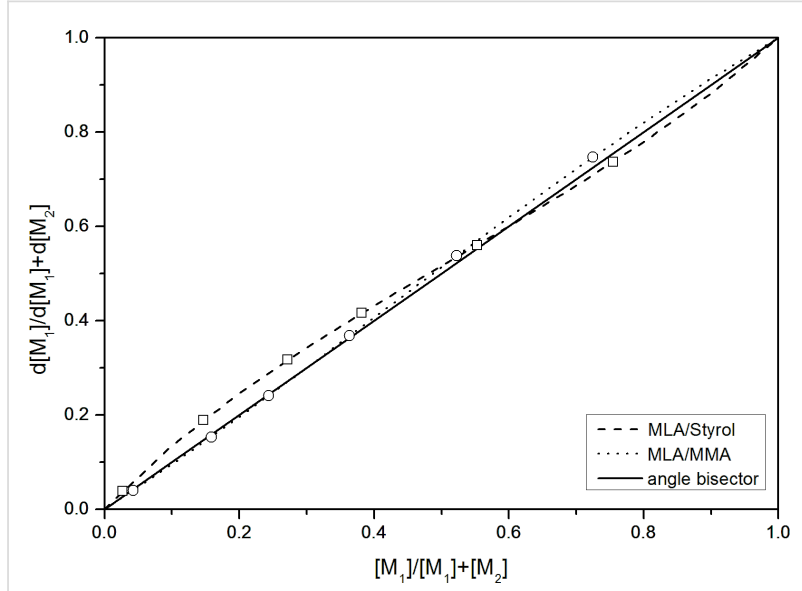

Figure 7: Copolymer composition curves for the systems MLA with styrene and MMA.

\section{Chain-transfer agents for free-radical poly- merization}

Attempts to reduce the molecular weight during the MLA polymerization by the use of classical chain-transfer agents such as mercaptoethanol, mostly failed (Figure S17 and Table S7, Supporting Information File 1). A preferred nucleophilic attack of the thiol takes place. This can be clearly seen in the ${ }^{1} \mathrm{H}$ NMR spectra (Figures S18 and S19, Supporting Information File 1).

Thioacetic acid was used as a potential chain-transfer agent due to its lower nucleophilicity. However, a complete thiol-Michael addition can be seen in Figure 8 (not full conversion of MLA due to the impurities of thioacetic acid like disulfide and acetic acid). In this context, the iodine catalyzed thiol-Michael addition was investigated [11].

\section{Controlled radical polymerization of MLA via RAFT}

Since MLA acts as a vinyl monomer, it was also interesting to evaluate the controlled RAFT mechanism. Recently, the MADIX (macromolecular design via the interchange of xanthates) technique was found to be unsuccessful for the controlled radical homopolymerization of the non-cyclic monomer EAA. Only in the presence of acrylic monomers copolymerization of EAA under MADIX conditions was possible [23]. For MLA polymerization under controlled radical conditions, we evaluated a similar type of polymerization, the RAFT mechanism as shown in Scheme 3. The reversible series of addition and fragmentation between dormant and active chain ensure uniform growth of all chains with narrow dispersity $(\nexists)$. 


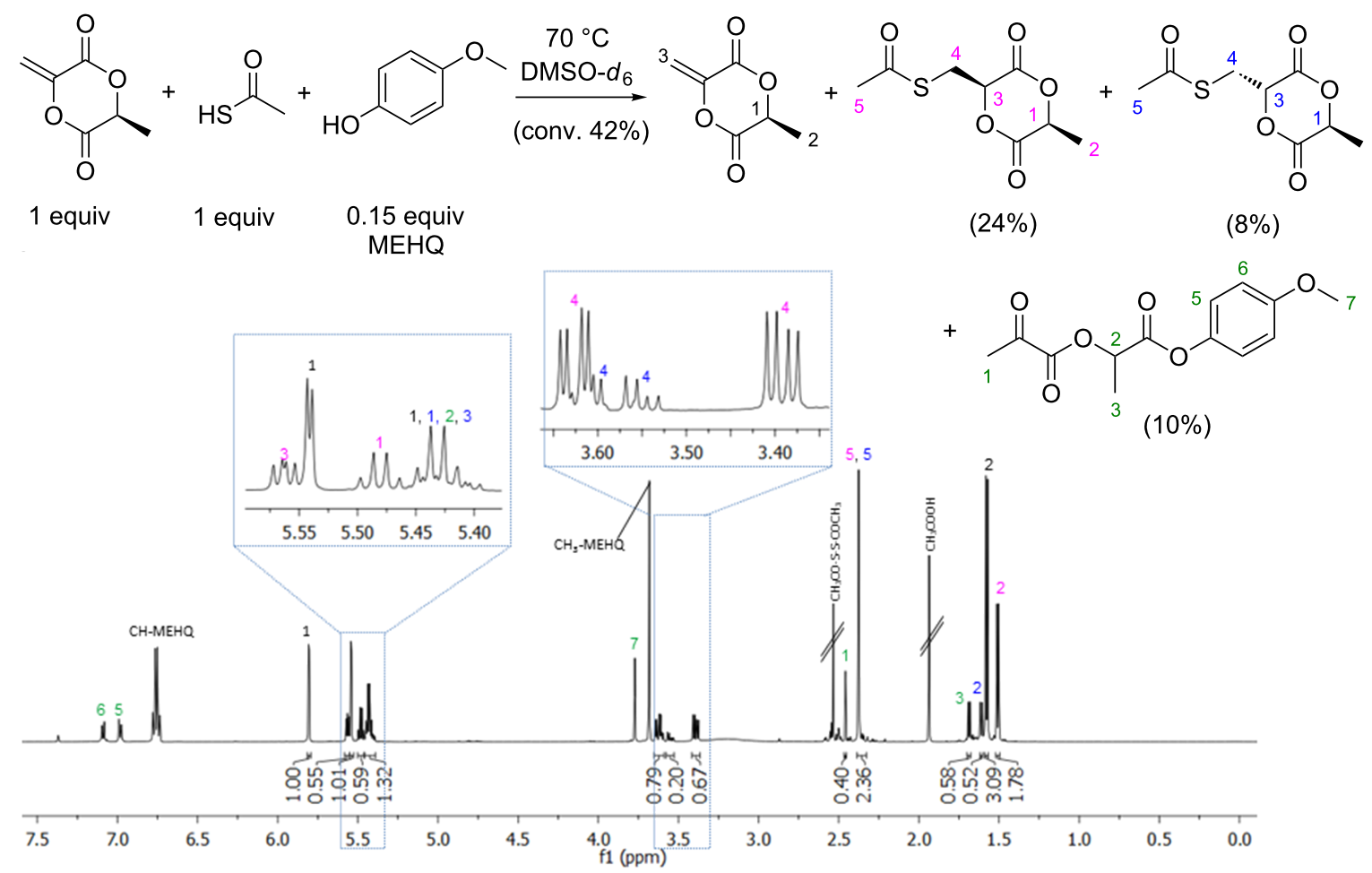

Figure 8: ${ }^{1} \mathrm{H}$ NMR spectrum of MLA with 1 equiv of thioacetic acid and 0.15 equivalents of an inhibitor 4-methoxyphenol (MEHQ) measured after $30 \mathrm{~min}$ at $70{ }^{\circ} \mathrm{C}$ in a NMR spectrometer $\left(600 \mathrm{MHz}\right.$, DMSO- $\left.d_{6}, 70{ }^{\circ} \mathrm{C}, c_{\mathrm{MLA}}=c_{\text {Thioacetic acid }} 0.5 \mathrm{~mol} \cdot \mathrm{L}^{-1}\right)$.

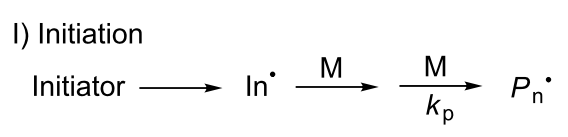

II) Pre-equilibrium/reversible chain transfer

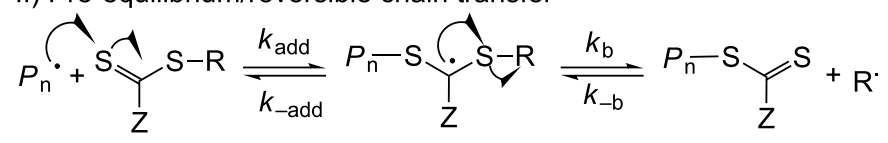

III) Reinitiation

$$
\mathrm{R} \cdot \stackrel{\mathrm{M}}{k_{\mathrm{i}}} \mathrm{R}-\mathrm{M} \cdot \stackrel{\mathrm{M}}{\longrightarrow} \frac{\mathrm{M}}{k_{\mathrm{p}}} P_{\mathrm{m}} \cdot
$$

IV) Main equilibrium/chain equilibriation

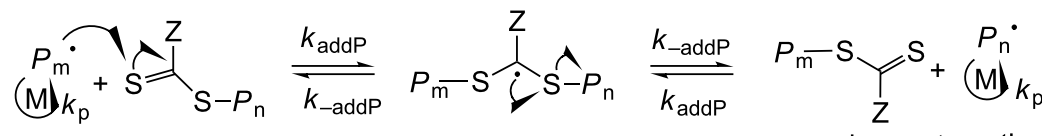

$$
\begin{aligned}
& \text { active dormant } \\
& \text { dormant active }
\end{aligned}
$$

V) Termination

$$
P_{\mathrm{n}}+P_{\mathrm{m}} \stackrel{k_{\mathrm{t}}}{\longrightarrow} \text { dead polymer }
$$

Scheme 3: Mechanism of RAFT polymerization [24].

The general structures of the RAFT agents contain a thiocarbonylthio group with reactive $\mathrm{C}-\mathrm{S}$ double bond and attached Rand Z-group, whereas MADIX only refers to xanthates. Four
RAFT agents with different polarities based on trithiocarbonate were examined in the RAFT homopolymerization of MLA (Figure 9). 
<smiles>C[Br+]Br</smiles><smiles>CCSC(=S)SC(C)(C#N)CCC(=O)O</smiles><smiles>CCOC(=O)C(C)(C#N)SC(=S)OCC(C)(C)C</smiles><smiles>CCSC(=S)SC(C)(C)C(=O)O</smiles>

Figure 9: Structures of used RAFT agents examined in the polymerization of MLA.

The data of the RAFT homopolymerization of MLA are summarized in Table 3. Only in the presence of the more polar 4-cyano-4-(((ethylthio)carbonothioyl)thio)pentanoic acid (CTA) and 2-(((ethylthio)carbonothioyl)thio)-2-methylpropanoic acid (EMP) a polymerization took place. However only with EMP narrow dispersity was achieved $(\fallingdotseq=1.6)$. This dispersity of 1.6 illustrates the upper limit for a successful RAFT process. Beside the good dispersity, the $M_{\mathrm{n}}$ in comparison to the theoretical value $M_{\mathrm{n}}$ theo. is much higher due to the known parallel running process of self-initiation. For this reason, the polymerization with EMP was further examined.
Upon further experiments with EMP (Table 4), the self-initiation becomes evident. Run 6 show the extent of the self-initiation with $M_{\mathrm{n}}$ of $17200 \mathrm{~g} \mathrm{~mol}^{-1}$ and $Ð=2$. A reduced amount of MLA result in bimolecular $M_{\mathrm{n}}$ (run 7, Table 4) and a doubling of the amount of MLA in much higher $M_{\mathrm{n}}$ (runs 8 and 9, Table 4), by the dominant part of self-initiation. The runs in dry DMF seem to be better in terms of $M_{\mathrm{n}}$, but in terms of dispersity, too high for the RAFT process (runs 10 and 11, Table 4). The isotacticity of the MLA polymers obtained in the RAFT polymerization was identical to those measured in the free-radical polymerization (Figure S20, Supporting Information File 1). The RAFT copolymerization with $N, N$-dimethylacrylamide (DMA) was investigated to reduce the self-initiated part [23].

\section{RAFT-Copolymerization of MLA with $\mathrm{N}, \mathrm{N}$-dimethylacrylamide (DMA)}

Copolymerization of MLA with DMA was conducted aiming for copolymers with a molecular weight of $M_{\mathrm{n}}$ of $20000 \mathrm{~g} \mathrm{~mol}^{-1}$. The results of the RAFT copolymerization are summarized in Table 5 (see SEC traces Figure S21, Supporting Information File 1).

As expected, the $M_{\mathrm{n}}$ values come closer to the theoretical values, the more DMA is used (Figure S21, Supporting Information File 1). At runs 12, 14 and 16 (Table 5) the MLA

\begin{tabular}{|c|c|c|c|c|c|c|}
\hline run & $\begin{array}{c}{[1] / \mathrm{RAFT} /[\mathrm{AIBN}]} \\
{[\mathrm{mol} \%]}\end{array}$ & $\begin{array}{l}\text { Time } \\
{[\mathrm{h}]}\end{array}$ & $\begin{array}{c}\text { Conversion } \\
{[\%]}\end{array}$ & $\begin{array}{l}M_{\mathrm{n} \text { theo }}{ }^{\mathrm{a}} \\
{[\mathrm{g} / \mathrm{mol}]}\end{array}$ & $\begin{array}{l}M_{\mathrm{n} \mathrm{SEC}}{ }^{\mathrm{b}} \\
{[\mathrm{g} / \mathrm{mol}]}\end{array}$ & $\oplus$ \\
\hline 1 & 98.87/DBTTC/0.125 & 16 & 2.7 & - & - & - \\
\hline 2 & 98.87/CPDTTC/0.125 & 16 & 4.2 & - & - & - \\
\hline 3 & 98.87/CTA/0.125 & 18 & 87 & 12500 & 55400 & 2.3 \\
\hline 4 & 98.87/EMP/0.125 & 16 & $>99$ & 1430 & 43000 & 1.6 \\
\hline
\end{tabular}

${ }^{\mathrm{a} C}$ Calculated theoretical molecular weights see characterization method in Supporting Information File 1. ' $\mathrm{b}$ Determined by PS-calibrated SEC.

Table 4: RAFT homopolymerization of MLA with EMP (80 wt \% 1,4-dioxane at $\left.70{ }^{\circ} \mathrm{C}\right)$.

\begin{tabular}{|c|c|c|c|c|c|c|}
\hline run & $\begin{array}{c}{[\mathrm{MLA}] /[\mathrm{EMP}] /[\mathrm{AIBN}]} \\
{[\mathrm{mol} \%]}\end{array}$ & $\begin{array}{c}\text { Time } \\
\text { [h] }\end{array}$ & $\begin{array}{c}\text { Conversion } \\
{[\%]}\end{array}$ & $\begin{array}{l}M_{\mathrm{n}} \text { theo } \\
{[\mathrm{g} / \mathrm{mol}]}\end{array}$ & $\begin{array}{l}M_{\mathrm{n} \mathrm{SEC}}{ }^{\mathrm{b}} \\
{[\mathrm{g} / \mathrm{mol}]}\end{array}$ & 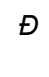 \\
\hline 4 & $98.87 / 1 / 0.125$ & 16 & $>99$ & 14300 & 43000 & 1.6 \\
\hline 5 & $98.87 / 0 / 0.125$ & 17 & $>99$ & 79100 & 35800 & 2.3 \\
\hline 6 & $98.87 / 0 / 0$ & 16 & 100 & - & 17200 & 2.0 \\
\hline 7 & $49.44 / 1 / 0.125$ & 16 & 97 & 7000 & 16600 & 1.5 \\
\hline 8 & $197.74 / 1 / 0.125$ & 18 & $>99$ & 28300 & 191300 & 2.4 \\
\hline $9^{c}$ & $197.74 / 1 / 0.125$ & 18 & 58 & 16400 & 80900 & 1.9 \\
\hline $10^{d}$ & $197.74 / 1 / 0.125$ & 20 & 92 & 26200 & 18500 & 1.9 \\
\hline $11^{d}$ & $98.87 / 1 / 0.125$ & 18 & 70 & 10000 & 50000 & 2.2 \\
\hline
\end{tabular}

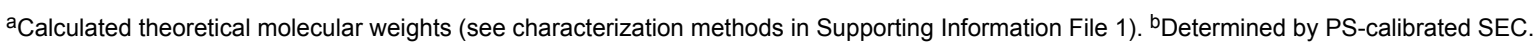
${ }^{c} 180$ wt $\%$ of 1,4 -dioxane. ${ }^{d} 80$ wt $\%$ dry DMF as solvent. 
Table 5: RAFT copolymerization of MLA with DMA ( $0.5 \mathrm{~mol} \%$ EMP and $0.0625 \mathrm{~mol} \%$ AIBN, 80 wt $\% 1,4$-dioxane, $\left.70{ }^{\circ} \mathrm{C}\right)$.

\begin{tabular}{|c|c|c|c|c|c|c|c|}
\hline run & $\begin{array}{c}{[\mathrm{DMA}] /[\mathrm{MLA}]} \\
{[\mathrm{mol} \%]^{\mathrm{a})}}\end{array}$ & $\begin{array}{l}\text { Time } \\
{[\mathrm{h}]}\end{array}$ & $\begin{array}{c}\text { Conversion } \\
{[\%]^{a)}}\end{array}$ & $\begin{array}{c}M_{\mathrm{n} \text { theo }}{ }^{\mathrm{a}} \\
{[\mathrm{g} / \mathrm{mol}]}\end{array}$ & $\begin{array}{c}M_{\mathrm{n} \mathrm{SEC}}{ }^{\mathrm{b}} \\
{[\mathrm{g} / \mathrm{mol}]}\end{array}$ & 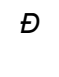 & $\begin{array}{c}T_{\mathrm{g}} \\
{\left[{ }^{\circ} \mathrm{C}\right]}\end{array}$ \\
\hline 12 & $50 / 50$ & 18 & $43 / 91$ & 17400 & 31200 & 1.6 & 193 \\
\hline 13 & $75 / 25$ & 18 & $100 / 100$ & 22200 & 29300 & 1.3 & 149 \\
\hline 14 & $85 / 15$ & 18 & $72 / 100$ & 16600 & 22300 & 1.3 & 139 \\
\hline 15 & $90 / 10$ & 18 & $100 / 100$ & 20900 & 28800 & 1.2 & 131 \\
\hline 16 & $95 / 5$ & 18 & $63 / 100$ & 13400 & 22200 & 1.3 & 127. \\
\hline 17 & $100 / 0$ & 18 & 100 & 19900 & 20400 & 1.2 & 121 \\
\hline
\end{tabular}

${ }^{\mathrm{a} C}$ Calculated theoretical molecular weights (see characterization methods in Supporting Information File 1). ${ }^{\mathrm{b}}$ Determined by PS-calibrated SEC.

revenues were not quantitative with a slightly lower dispersity may be due to a longer induction period, but this also occurred in the repetition in other runs.

To investigate the process of the RAFT copolymerization of DMA with MLA the semi-logarithmic plot of conversion against time of run 15 (ratio 90/10, Table 5) was conducted which shows linearity for both monomers after a very short induction period (Figure 10A). This linearity confirmed a constant radical concentration during the copolymerization. MLA was converted quite rapidly in comparison to DMA. Therefore, the copolymerization trend seems to follow a gradient copolymer. This copolymerization process can be also identified in Figure 10B in which the highest value of the dispersity $(\nexists=1.35)$ corresponds to a quantitative conversion of MLA but to approximately $20 \%$ of the total revenue. After this point, the dispersity reduces until 1.23 , corresponding to a dominant DMA part. An evidence for the gradient copolymerization can be found in the ${ }^{1} \mathrm{H}$ NMR spectrum by two separate lactide
$\mathrm{CH}$ signals for the part of MLA and the copolymer part with DMA (Figure S22, Supporting Information File 1). In addition, at low conversion a rapid increase of the molecular weight of $M_{\mathrm{n}}=4000 \mathrm{~g} \mathrm{~mol}^{-1}\left(M_{\mathrm{n} \text { theo }}=1300 \mathrm{~g} \mathrm{~mol}^{-1}\right)$ can be observed (Figure S23 and Table S8, Supporting Information File 1). This observation has already been described in the literature and termed "hydrid behavior". It is characterized by a rapid increase in molecular weight in the initial stage due to deviation from the ideal kinetic behavior, leading to a mixed form of free radical and controlled radical polymerization followed by a controlled increase in molecular weight up to high monomer conversions which is responsible for the poor matches to the theoretical $M_{\mathrm{n}}$ values.

The semi-logarithmic plot of conversion against time of run 13 (ratios $75 / 25$, Table 5) refer to Figure S24 show almost linearity for MLA, but with low conversion compared to the known rapid polymerization behavior. However, from the beginning until $8 \mathrm{~h}$ no conversion of DMA was observed, the
A)

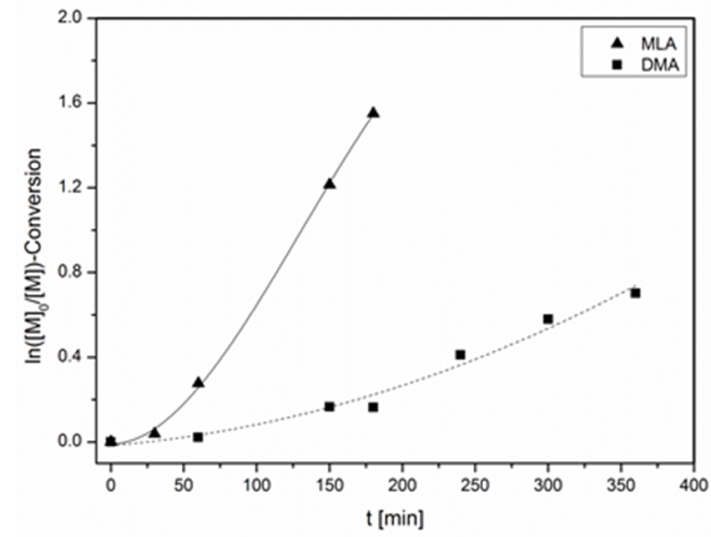

B)

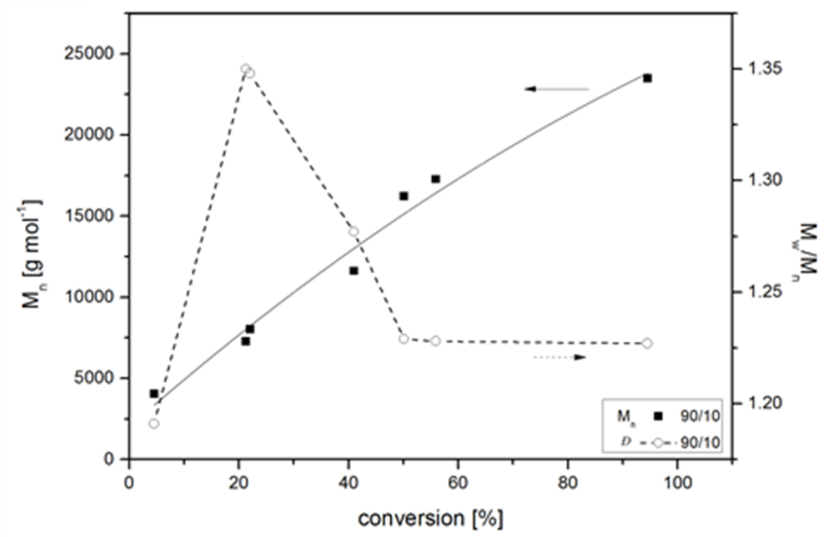

Figure 10: A) Kinetic plot for the RAFT copolymerization of MLA and DMA for the ratio 90/10 employing EMP. B) The evolution of $M_{\mathrm{n}}$ (full symbols) and $\Theta$ (empty symbols) with conversion of the copolymerization. 
finally 55\% conversion of DMA were achieved afterwards until $22 \mathrm{~h}$. The evolution of $M_{\mathrm{n}}$ and $Ð$ with conversion could not be evaluated due to overlapping signals in the SEC with the solvent DMF. Only at the end of the kinetic at $22 \mathrm{~h}$ the copolymer shows a useful value of $M_{\mathrm{n}}=10700 \mathrm{~g} \mathrm{~mol}^{-1}$ and $Ð=1.6$ with incorporated ratio of DMA/MLA of $60 / 40$ determined by ${ }^{1} \mathrm{H}$ NMR spectroscopy. The theoretical molecular weight $M_{\mathrm{n} \text { theo }}=14000 \mathrm{~g} \mathrm{~mol}^{-1}$ is higher than the achieved $M_{\mathrm{n}}$ which is a sign for the occurrence of transfer reactions. However, in the repetition of the kinetic of run 13 (Table 5) the conversion started with linearity for both monomers after an induction period (refer to Figure S24, Supporting Information File 1) with otherwise the same results (conv. MLA completely and DMA $65 \%$, at $24 \mathrm{~h} M_{\mathrm{n}}=13400 \mathrm{~g} \mathrm{~mol}^{-1}$ with $Ð=1.6\left(M_{\mathrm{n}}\right.$ theo of $\left.17000 \mathrm{~g} \mathrm{~mol}^{-1}\right)$ ).

These findings support the thesis that the copolymerization process of DMA and MLA is based on gradient copolymerization. The low conversion of MLA could be based on a slowly occurring sequence of addition and fragmentation between dormant and active chains because of the radical stabilized by the push-pull substituents. However, with this result it has been shown that the RAFT polymerization is a successful technique for MLA to achieve (co)polymers with narrow dispersities and with almost low molecular weight.

\section{Conclusion}

This first detailed study on the radical polymerization behavior of the cyclic push-pull-type monomer methylenelactide has been conducted. This was performed in comparision to the analogous non-cyclic push-pull-type monomers methyl $\alpha$-acetoxyacrylate (MAA), ethyl $\alpha$-acetoxyacrylate, (EAA) and pull-type methyl methacrylate (MMA) and cyclic pull-type $\alpha$-methylene$\delta$-valerolactone (MVL).

A deviation from classical free-radical polymerization kinetics was found and correlated with significant self-initiation. A mechanism for the radical formation was proposed and supported by theoretical calculations. With the help of a strongly colored 1,1-diphenyl-2-picrylhydrazyl radical (DPPH) the spontaneous radical formation could also be observed by the naked eye. Furthermore, the copolymerization parameters of MLA with styrene and MMA were obtained and the $Q$ and $e$ values calculated. The latter allows the prediction of the copolymerization process with further monomers. Finally, this work reports on the first controlled polymerization of methylenelactide and controlled copolymerization with $N, N$-dimethylacrylamide via RAFT technique. From the above presented results it can be summarized that MLA represents a highly reactive monomer with a potential for many practical applications and further investigations.

\section{Supporting Information}

Full experimental section containing the description of the materials, characterization methods and syntheses of the obtained polymers, spectroscopic data $\left({ }^{1} \mathrm{H},{ }^{13} \mathrm{C}\right.$ and IR), ${ }^{1} \mathrm{H}$ NMR kinetics, UV-vis measurements, polymerization analytics to determine the chain transfer constant, SEC curves of the RAFT initiated (co)polymers, the determination of the copolymerization parameters $Q$ and $e$ values and force constant.

\section{Supporting Information File 1 \\ Experimental part. \\ [http://www.beilstein-journals.org/bjoc/content/ supplementary/1860-5397-12-232-S1.pdf]}

\section{References}

1. Viehe, H. G.; Janousek, Z.; Merenyi, R.; Stella, L. Acc. Chem. Res. 1985, 18, 148-154. doi:10.1021/ar00113a004

2. Scheibelhoffer, A. S.; Blose, W. A.; Harwood, H. J. Polym. Prepr. (Am. Chem. Soc., Div. Polym. Chem.) 1969, 10, 1375-1380.

3. Jing, F.; Hillmyer, M. A. J. Am. Chem. Soc. 2008, 130, 13826-13827. doi:10.1021/ja804357u

4. Fiore, G. L.; Jing, F.; Young, V. G., Jr.; Cramer, C. J.; Hillmyer, M. A. Polym. Chem. 2010, 1, 870-877. doi:10.1039/c0py00029a

5. Barker, I. A.; Hall, D. J.; Hansell, C. F.; Du Prez, F. E.; O'Reilly, R. K.; Dove, A. P. Macromol. Rapid Commun. 2011, 32, 1362-1366. doi:10.1002/marc.201100324

6. Castillo, J. A.; Borchmann, D. E.; Cheng, A. Y.; Wang, Y.; Hu, C.; García, A. J.; Weck, M. Macromolecules 2012, 45, 62-69. doi:10.1021/ma2016387

7. Britner, J.; Ritter, H. Macromolecules 2015, 48, 3516-3522. doi:10.1021/acs.macromol.5b00040

8. Mauldin, T. C.; Wertz, J. T.; Boday, D. J. ACS Macro Lett. 2016, 5, 544-546. doi:10.1021/acsmacrolett.6b00023

9. Miyake, G. M.; Zhang, Y.; Chen, E. Y.-X. J. Polym. Sci., Part A: Polym. Chem. 2015, 3, 1523-1532. doi:10.1002/pola.27629

10. Kalelkar, P. P.; Alas, G. R.; Collard, D. M. Macromolecules 2016, 49, 2609-2617. doi:10.1021/acs.macromol.5b02431

11. Long, T. R.; Wongrakpanich, A.; Do, A.-V.; Salem, A. K.; Bowden, N. B. Polym. Chem. 2015, 6, 7188-7195. doi:10.1039/C5PY01059D

12. Fuoco, T.; Finne-Wistrand, A.; Pappalardo, D. Biomacromolecules 2016, 17, 1383-1394. doi:10.1021/acs.biomac.6b00005

13. Tanaka, H.; Kunouchi, Y.; Takeichi, T. Macromolecules 1997, 30 , 4010-4012. doi:10.1021/ma9702253

14. Ueda, M.; Takahashi, M.; Imai, Y.; Pittman, C. U. Macromolecules 1983, 16, 1300-1305. doi:10.1021/ma00242a009

15. Tanaka, H.; Matsubara, Y.; Kusunoki, K.; Saito, N.; Kibayashi, T. J. Polym. Sci., Part A: Polym. Chem. 2015, 53, 2007-2016. doi:10.1002/pola.27649

16. Reichardt, C.; Welton, T. Solvents and Solvent Effects in Organic Chemistry, 4th ed.; Wiley-VCH: Weinheim, Germany, 2011. doi:10.1002/9783527632220 
17. Tanaka, H.; Kameshima, T.; Sasai, K.; Sato, T.; Ota, T. Makromol. Chem. 1991, 192, 427-435. doi:10.1002/macp.1991.021920222

18. Kelen, T.; Tüdös, F. J. Macromol. Sci., Chem. 1975, 9, 1-27. doi:10.1080/00222337508068644

19. Alfrey, T., Jr.; Price, C. C. J. Polym. Sci. 1947, 2, 101-106. doi:10.1002/pol.1947.120020112

20. Unruh, C. C.; Laakso, T. M. J. Polym. Sci. 1958, 33, 87-94. doi:10.1002/pol.1958.1203312609

21. Greenley, R. Z. J. Macromol. Sci., Chem. 1975, 9, 505-516. doi:10.1080/00222337508065873

22. Hongo, T.; Yoshida, S.; Yamada, T.; Tanaka, H. Polym. Int. 1999, 48, 505-508. doi:10.1002/(SICI)1097-0126(199906)48:6<505::AID-PI182>3.0.CO;22

23. Batt-Coutrot, D.; Robin, J.-J.; Bzducha, W.; Destarac, M. Macromol. Chem. Phys. 2005, 206, 1709-1717. doi:10.1002/macp.200500065

24. Barner-Kowollik, C., Ed. Handbook of RAFT Polymerization; Wiley-VCH: Weinheim, Germany, 2008. doi:10.1002/9783527622757

\section{License and Terms}

This is an Open Access article under the terms of the Creative Commons Attribution License (http://creativecommons.org/licenses/by/4.0), which permits unrestricted use, distribution, and reproduction in any medium, provided the original work is properly cited.

The license is subject to the Beilstein Journal of Organic Chemistry terms and conditions:

(http://www.beilstein-journals.org/bjoc)

The definitive version of this article is the electronic one which can be found at: doi:10.3762/bjoc. 12.232 